\title{
Letter to the editor: reviewing reviewers and reanalysing meta-analyses of stapled haemorrhoidopexy?
}

\author{
Johannes Jongen • Sven Petersen
}

Accepted: 2 April 2009 / Published online: 18 April 2009

(C) Springer-Verlag 2009

Sir,

Reviewing reviewers and reanalysing meta-analyses of stapled haemorrhoidopexy?

Writing reviews and performing meta-analyses should save readers from doing this tedious work themselves. However, they should be able to rely on the quality of the studies included, especially if they are not familiar themselves with the analysed procedures. Having written comments on such meta-analyses, we feel like "Statler and Waldorf" sitting on the balcony and addressing our concerns on this sort of reviews on procedure for prolapse and haemorrhoids.

Reading the review by Laughan et al., we found publications that might not have been suitable. In this

Manuscript/Letter to the editor on: Laughlan K, Jayne DG, Jackson D, Rupprecht F, Ribaric G (2009) Stapler haemorrhoidopexy compared to Milligan-Morgan and Ferguson haemorrhoidectomy: a systemic review. Int $J$ Colorectal Dis 24:335-344

\section{J. Jongen}

Department of Proctological Surgery, Park-Klinik, Kiel, Germany

\section{S. Petersen}

First Department of Surgery, Asklepios-Hospital Altona, Hamburg, Germany

\section{J. Jongen $(\bowtie)$}

Proctological Office Kiel,

Beselerallee 67,

24105 Kiel, Germany

e-mail: jjongen@proktologie-kiel.de context, the publication of Khalil et al. needs to be mentioned. This is a paper in which a linear stapler is used. This is also described in the paper itself, and the authors refer to a short note by O'Bichere from 1997. In this paper, a drawing of the linear cutter is shown. From the results published by Ganio et al., Laughlan et al. count two prolapses, although Ganio et al. write that only "six of nine patients" had cutaneous fibrous folds. To our understanding, at least three (and not two) patients had residual or recurrent prolapse.

It is believed that a meta-analysis of randomised trials is of highest evidence level. Nevertheless, the major concern with meta-analysis is the question which studies should be included. Laughan et al. included studies such as Lau et al. and Ortiz et al. with a caseload of approximately one haemorrhoidopexy per month, starting in 2001. The question arises if there was already sufficient expertise in these centres for an operation, which might need a sufficient learning curve.

In conclusion, if the selection criteria of studies are not consistent, good statistical work-up does not improve the analysis and conclusions and does not make the review more reliable! Therefore, the results of the review by Laughlan et al. need to be evaluated with caution. If reviews are done this way, readers might (we think, readers must) critically question the quality of such reviews! Reviews are good instruments to get a quick overview on a therapy, but if not done in a correct way, reviews and meta-analyses might be discredited.

Yours sincerely 